\title{
Floods in Sfax City: A Territorial Approach of Vulnerabilities Targeting Better Risks Management
}

\author{
Hmercha Hayet $^{1}$, Daoud Abdelkarim ${ }^{2}$, Saint-Gerand Thierry ${ }^{3}$ \\ ${ }^{1}$ Department of Education and Teaching, Gafsa University, Gafsa, Tunisia \\ ${ }^{2}$ Department of Geography, Sfax University, Sfax, Tunisia \\ ${ }^{3}$ UFR of Geography, Caen Lower Normandy University, Caen, France
}

\section{Email address:}

hayethmersha@hotmail.com (H. Hayet), daoudabdelkarim@yahoo.fr (D. Abdelkarim), thierry.saintgerand@unicaen.fr (S-G. Thierry)

\section{To cite this article:}

Hmercha Hayet, Daoud Abdelkarim,Saint-Gerand Thierry. Floods in Sfax City: A Territorial Approach of Vulnerabilities Targeting Better Risks Management. American Journal of Water Science and Engineering. Vol. 3, No. 6, 2017, pp. 72-79. doi: 10.11648/j.ajwse.20170306.12

Received: August 20, 2017; Accepted: October 31, 2017; Published: November 30, 2017

\begin{abstract}
Flood risks in urban areas constitute today an important research topic in geography, because of increasingly disastrous consequences of certain pluviometry events in more and more important cities. The urban area of Sfax in southern Tunisia, with 22000 hectares and 600,000 inhabitants was also affected, during the five last decades, by floods with recurrent catastrophic consequences. If the flood hazards at the base of these floods risks are relatively well known, the vulnerabilities of the involved stakes are much less. This paper aims to high light, using spatial analysis and GIS mapping, the effective links between territorial features of Sfax and flood processing conditions and proposes a new approach to the risks through a better characterization of its vulnerabilities, which seem largely related to economic factors, human and functioning spatial structures and shapes. The results have confirmed that the existing protection infrastructures of the of Sfax urban area are no longer adequate to deal with the new vulnerabilities, and that it is high time for the risk management of flood to be directed to wards the attenuation of these vulnerabilities by seeking solutions in a future installation by the adoption of a PPRF, one (CMP) and by the integration of risk of flood in the urban development.
\end{abstract}

Keywords: Sfax City, Floods, Vulnerability, Risks, GIS, Spatial Analysis

\section{Introduction}

The risks of flood, in any territory, can be apprehended as the conjunction between specific hazards and exposed vulnerable stakes [12]. All these elements would thus be characterized and analyzed in their interactions. The studies on the floods in the urban area of Sfax are today numerous enough to make it possible to refine the analysis of each one of the components of this risk.

The principal hypothesis of this paper assumes that despite the effects of the protective infrastructures in place, they are unsuited to the new vulnerabilities inherent in the last and current shape and working way of the city.

This work is structured in three parts. The first deals with general data on the floods in the urban area of Sfax and the existing infrastructures aiming at its protection. The second part exposes the elements of a new approach of the vulnerabilities, which preliminary results are exposed in the third part.

\section{A Still Vulnerable Urban Area Despite the Important Infrastructure of Protection}

\subsection{Important, Sometimes Exceptional Pluviometric Events}

During the last four decades, the urban area of Sfax knew several important pluviometric events, sometimes exceptional. If the annual average for station of Sfax-ElMaou (reference station, located in Sfax Airport) for the period going from 1901 to 1985 is 215 millimeters [3], this one can be lower than 100 millimeters: 37.1 in 1946/47; 52.5 in 1936/37, or much more higher: 604.4 in 1969/70; 430 in $1948 / 49 ; 414$ in $1975 / 76$ [4]. The floods in urban environment, which followed the events of October 1982 can be regarded as event of reference, since the recorded 
quantities of 24 hours on October 30th, 1982 had reached140.8 millimeters (period of return equal to 160 years), quantities recorded between on October 30 that 10p.m. and the following day at 11a.m.05 hours had reached 177.3 millimeters (period of return equal to 500 years) [14]. The damage of this extraordinary event was catastrophic from the human point of view (approximately 70 people carried by the risings) and equipment (estimated at the time to 47 million dinars). Topography is at the origin of a very strong natural vulnerability, since the urban area occupies a littoral plain with very weak slope, towards which several important wadis converge, as the map of the basin at the risks how's it below (figure 1). Strong interannual variability and interseasonal of precipitations seems much related on the Mediterranean mode and the types of circulation (mainly) only to the contemporary climate change, which appears especially by a significant trend with warming. On the level of precipitations, one rather notes a more important occurrence of the extraordinary events [5] of which the effects on the Man and his activities in the urban area are multiplied because of its vulnerabilities.

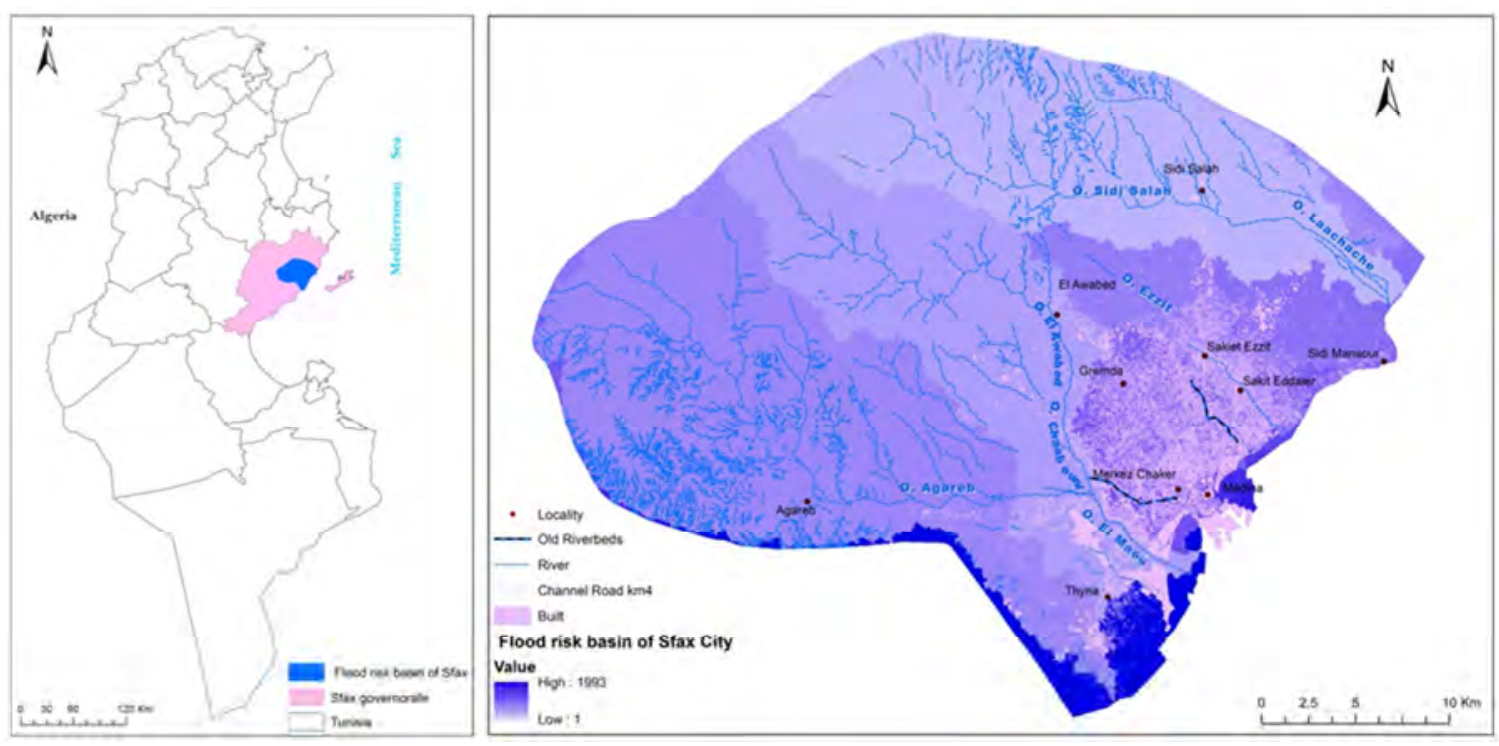

Figure 1. Basin at the risk of the urban area of Sfax.(Cartography Hmercha H.2015)

\subsection{Vulnerabilities: Multiple and Spatially Differentiated}

The floods of 1982 led the decision makers to equip the urban area of Sfax, with an imposing infrastructure of protection against the floods, installed in 1984 and comprising works of remote protection, mainly of the dams along the banks of wadis, and others of brought closer protection, mainly by means of a belt channel and channels having for role to intercept surface waters to evacuate them towards the sea.

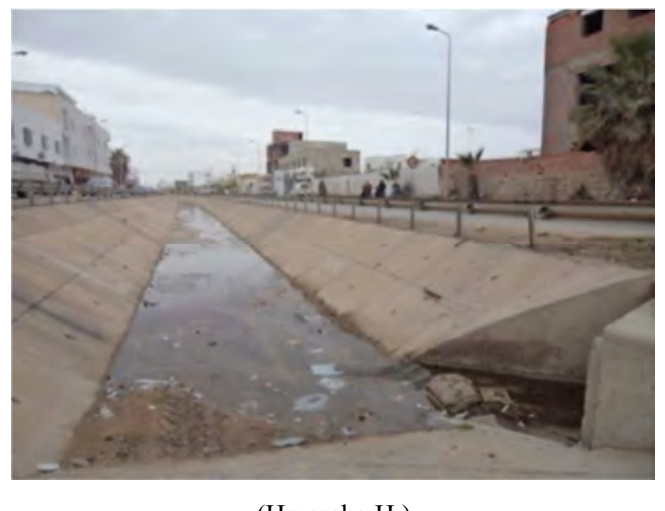

(Hmercha H.)

Figure 2. Channel Road km4;

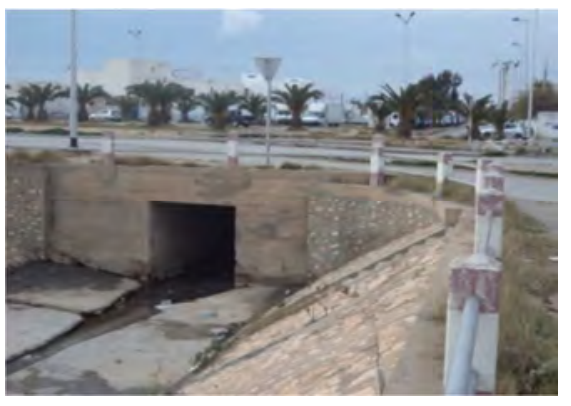

(Hmercha H.)

Figure 3. Rainwater drainage;

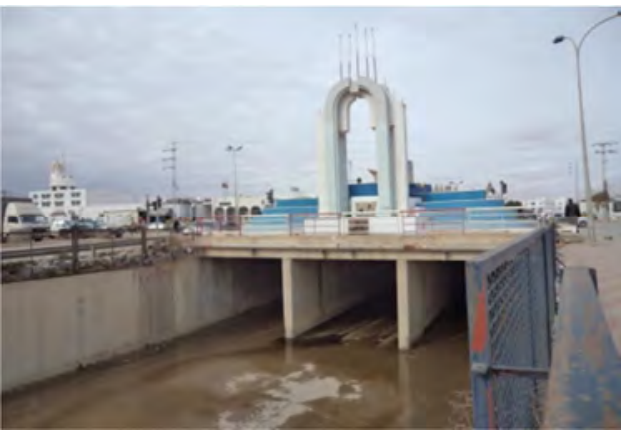

(Hmercha H.)

Figure 4. Oued Ezzit channel. 
This infrastructures how edits mettle for protection of the city by intercepting the risings before the arrival of water in the central and percentral zone (Figure 5).
This infrastructure made it possible to attenuate the vulnerability related to topography effects.

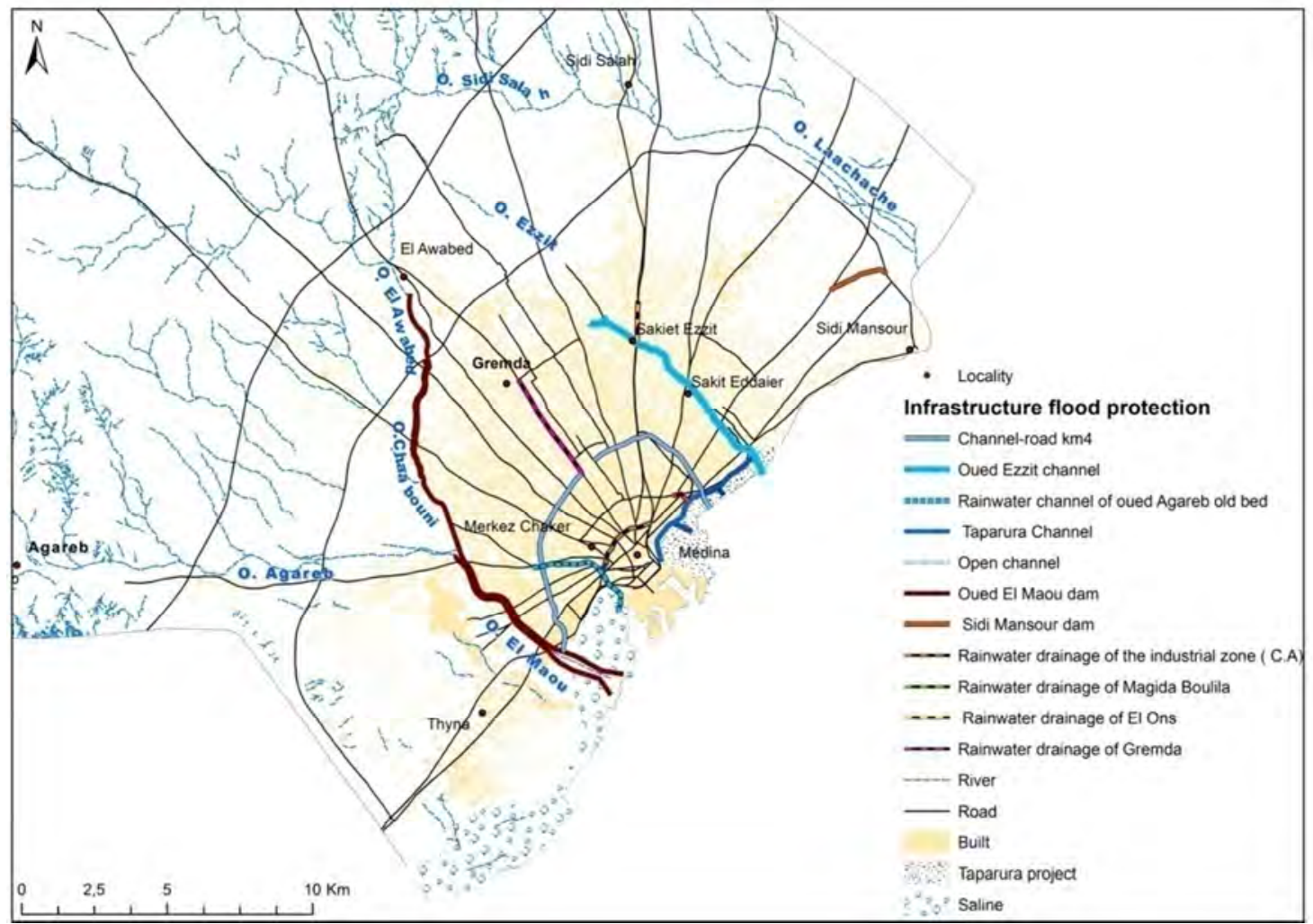

Figure 5. Infrastructure Flood Protection of the urban area of Sfax city. (Cartography Hmercha H. 2015).

However, urban growth and wide spreading occurred in the urban area since this installation [1] [2] generated new vulnerabilities, especially when the in regulatory habitat moved in the risky zones in edge of river or into their zones of spreading. Moreover, the evolution of the urban area was also marked by a remarkable enforcement of urban fabric, as well inside the zones power station and center neighbors as in sub urban habitat and a long radials (figure 7), which resulted in an increasingly important proofing of grounds.

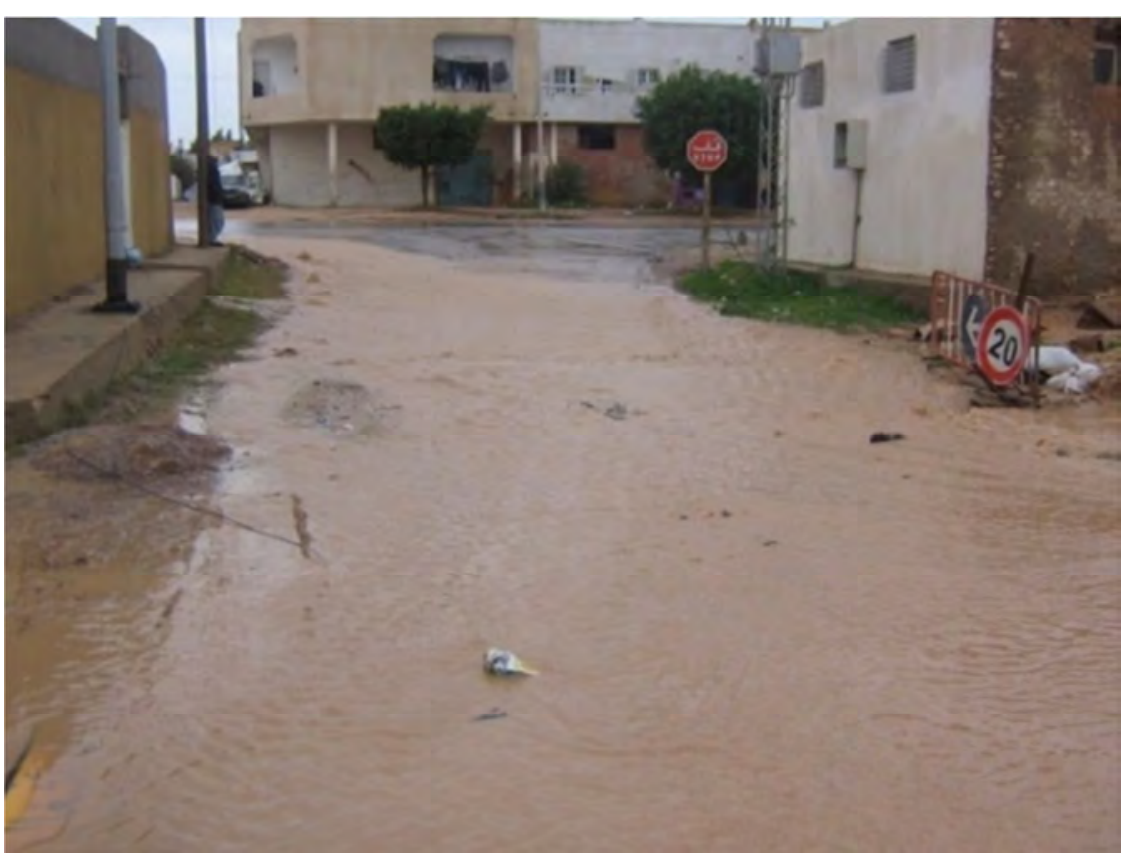

Figure 6. The course upstream of oued Ezzit strongly occupied today. Source: (DHU) Sfax 22-01-2009. 


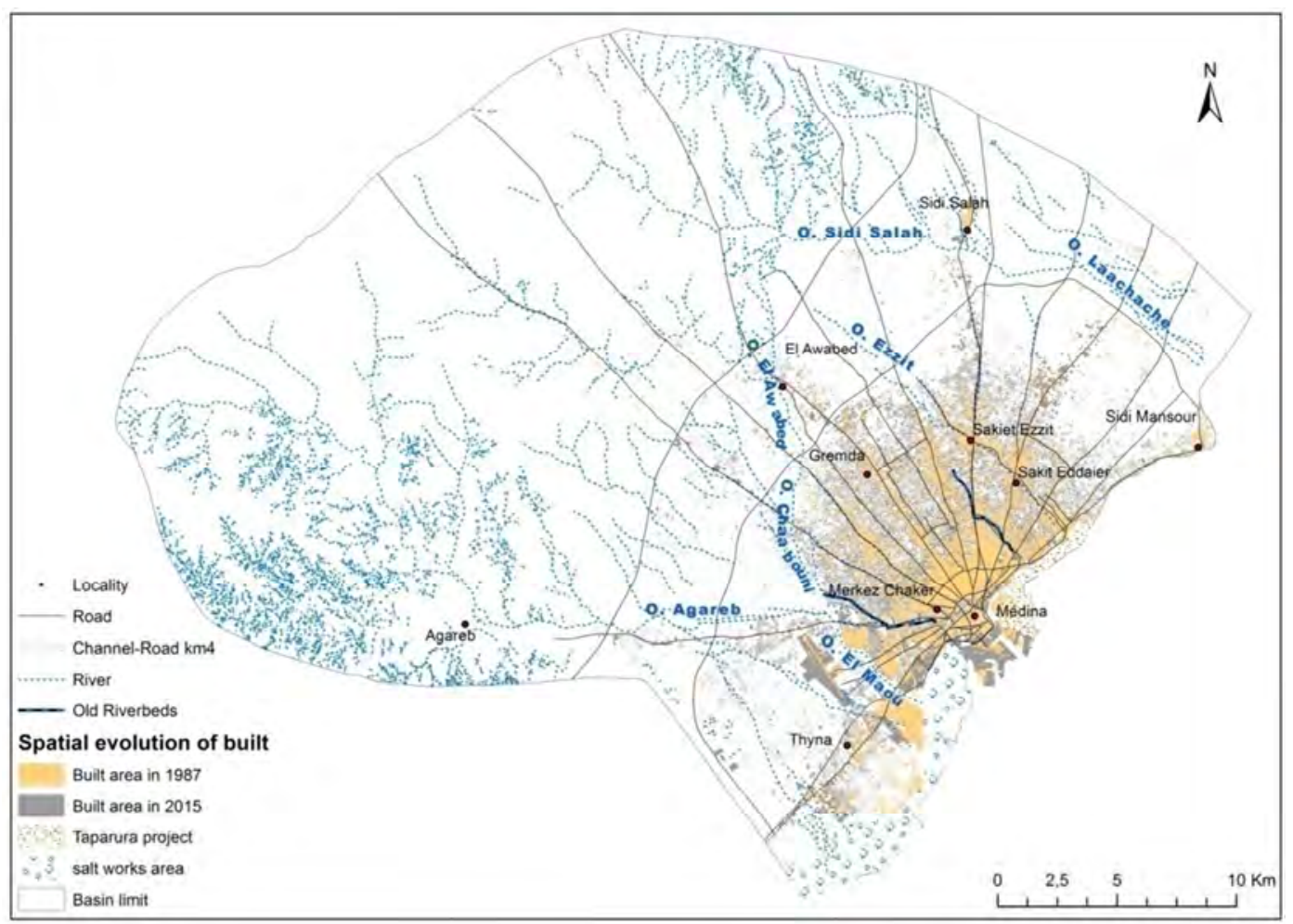

Figure 7. Space evolution of the frame in the urban area of Sfax between 1987 and 2015. (Cartography Hmercha H.2015)

The floods of 2003, and that of 2009 [1], like those more recent of 2013 and 2015 which particularly touched the downtown area and certain popular quarters located in very low zones topographically, close to the northern littoral of the city, revealed new vulnerabilities rather related to the intrinsic organization of the city, its transportation system and its very short operating process. Indeed, at the time of these events, sudden accumulations of water in the important cross roads and certain streets can lead to a temporary paralysis of certain small island sand important property damages in the infrastructures and means of transport.

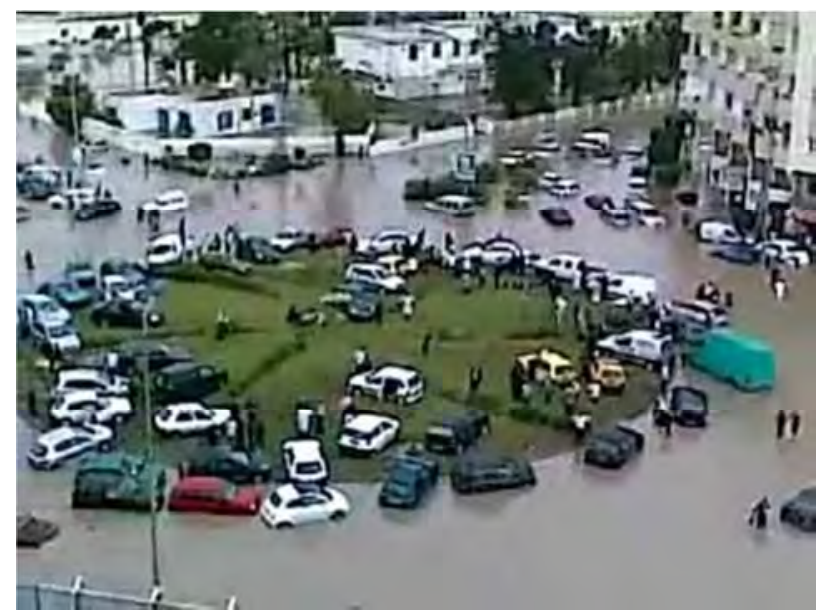

Figure 8. The floods of 2009(Daoud A.)

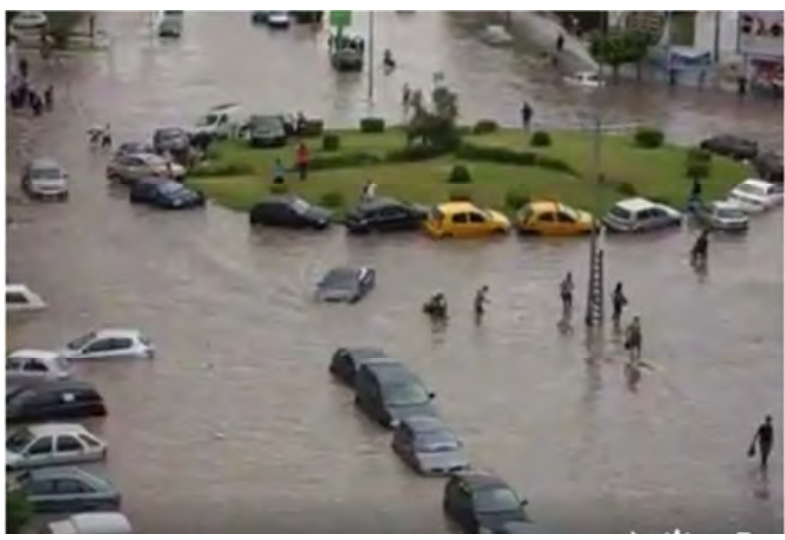

Figure 9. The floods of 2013 (Hmercha H.)

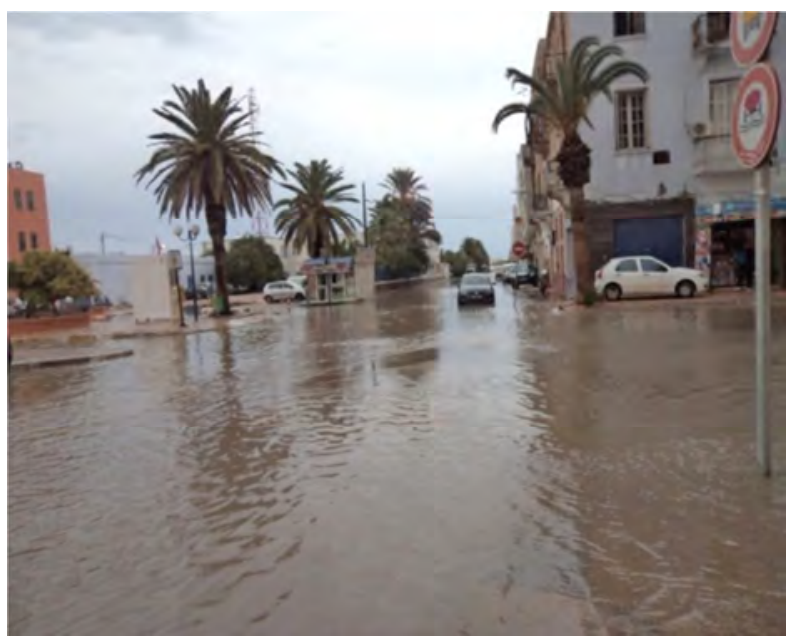

Figure 10. The floods of 2015 (Hmercha H.) 


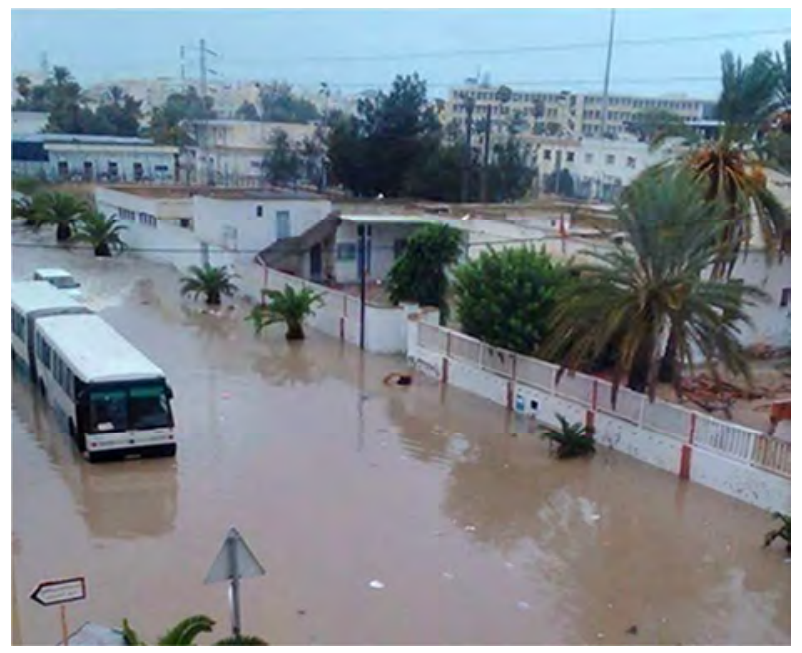

Figure 11. The floods of 2016

Figure 8, 9, 10, 11: Identical situation: Water blade wedges the roads of Sfax, on 2009, 2013, 2015 and 2016, the circulation stopped on several axes of the city disturbing the mobility of people and merchandises.

It is thus clear that the infrastructures of protection improved since 1984 permanently reach their capabilities limits. With these new vulnerabilities, other parades are necessary, but all must start with the finest possible space characterization, to understand their territorial interactions and their effects.

\section{Territorialisation of the Vulnerability and the Risks: Test of Modeling for the Urban Area of SFAX}

\subsection{Test of Conceptual Framing}

The approach of the risks through the vulnerability of the territories has its precursors. Without claiming to make an exhaustive list of it, let us note as example that for Thouret JC. and D'Ercole R [16], the knowledge of the urban vulnerability, would allow its estimated reduction before a crisis. On its side, November V. [11] and Saint-Gérand T. [15] use, in close meanings, the concept of situation at the risk. November V. in particular affirms that it should not be possible any more to study the risk without the territory, nor the territory without the risk...that means that the geographical studies of the risk must take account of the rich and complex relation between these two elements. For Laganier R. [7] to understand the relation between vulnerability, risk and territory would allow the best taken into account of this risk in the documents of town planning and of regional planning. Léone [8] note that distinction between three levels of vulnerability (and thus of risks) material, structural and functional, proves to be necessary to apprehend the systemic complexity of the urban risks.

The definition that we will retain of the vulnerability in this article is potential impact of an event on the various components of an exposed geographical territory. It depends especially on the resistance of the challenges, on the degree of the event and the sensitivity of a community to the risks. We will thus approach the territorial vulnerability of the urban area of Sfax by considering three great types of challenges and thus of vulnerability:

-Initially, body or human vulnerability, which is the potential impact of the hazard on the human life; it results from the intensity of the risk, the intrinsic sensitivity of population (perception, sensitivity...) and extrinsic (effectiveness of work of protections, alarm, the helps and the care...)

-Then the material or economic vulnerability, which is the potential impact of the hazard on the goods: the habitat, various types of buildings, various socio-economic activities of the company and transport networks and communication; it also depends on the intensity of the risk and on the physical capacity of resistance of the goods

-Finally, the functional vulnerability, which is the potential impact of the hazard on the operation of the city, it depends on the intensity of the risk but also of the capacity of resistance and impact strength of the territory.

\subsection{Material and Methods}

To get the most reliable possible results, a chain of methods was used. It consisted initially in satellite pictures operations: taking into account the non-availability of the data of the year 2000 on Google Earth and other sites, we had recourse to Land sat images http://landsat.usgs.gov/Landsat_Search_and_Download.phpa vailable free. The researchers managed to obtain the images of 1982 and 1987. Taking into account the resolution of these two images, the choice was naturally made on that of 1987. The bands charged (green, red, blue, infra-red, close infrared, average infra red and ultra violet) and were combined with the logiciel ENVI7 [10] for then passing to color composite. Once combined, with soft ware ArcGIS [9], we carried out the "supervised classification" which was followed of manual corrections to the base of knowledge of the ground. Four units of occupation were thus obtained at the conclusion of this treatment: not built frames and, sand and salt works. Then, we preceded to the digitalization of the data vectors of 2014. The digitalization systematically related to the frame, the network of roads and ways and the hydrographic network for the whole of the urban area.

In order to characterize the various types of vulnerabilities, which depend mainly on the mode of occupation of the ground, the method adopted in this work consists in counting the various fashions of occupation of the ground by paying a special attention to the sensitive installations like the schools, the hospitals, the poles chemical and industrial and unquestionable other sensitive installations of the zone of study. The total approach of space analysis of the human challenges [13] comprises the following phases: initially, the inventory of the space objects characterized by the presence of the population, their identification and classification according to various types of urban morphology. Then, determination of the levels of challenges and vulnerabilities 
of these units: estimate amongst people, characterization of the population and estimate of her degree of exposure.
Lastly, the cartography of vulnerability typologies of zones.

\subsection{Cartography of the Vulnerabilities in the Urban Area of Sfax: Preliminary Results}

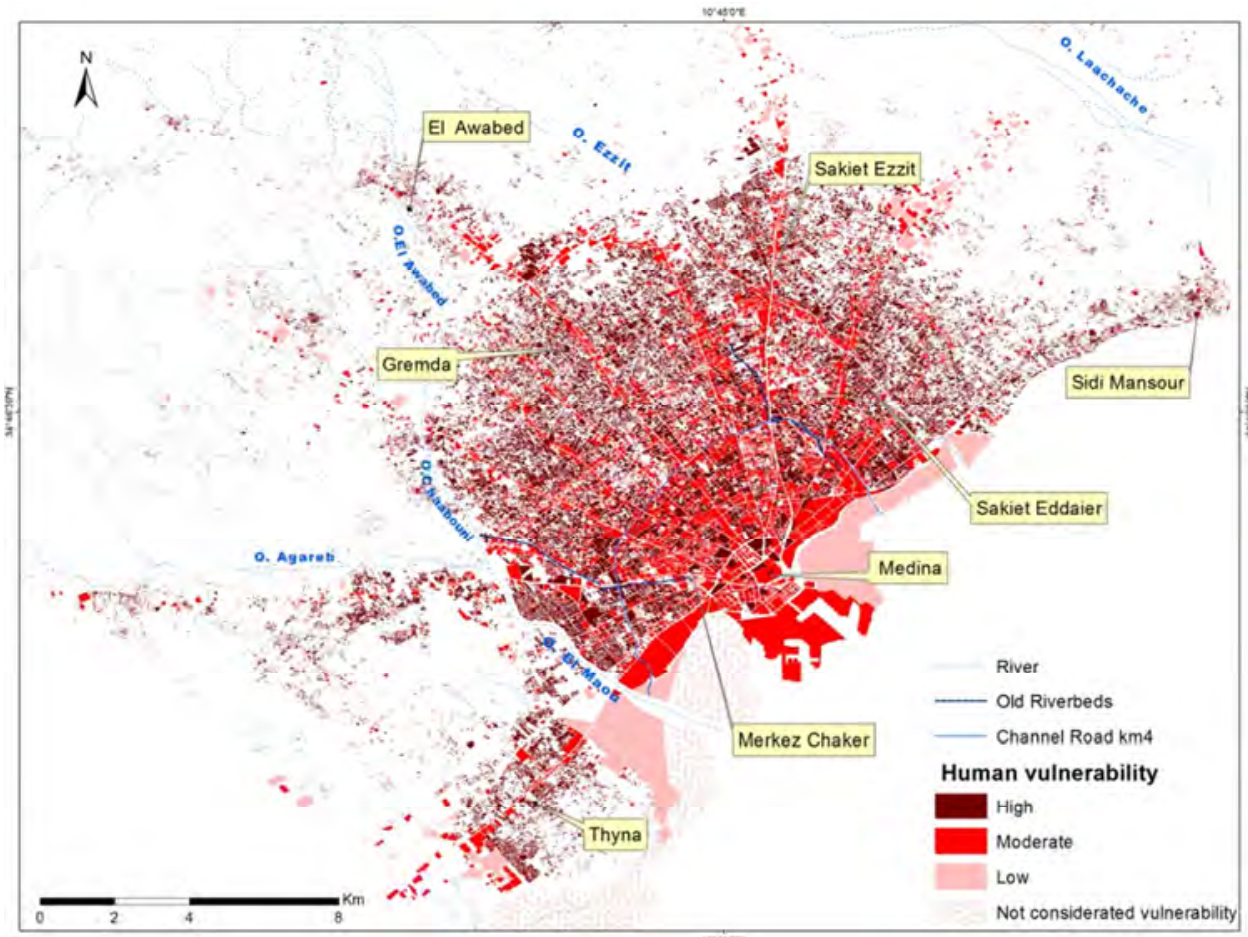

Figure 12. Map of the levels of human vulnerability in the urban area of Sfax.

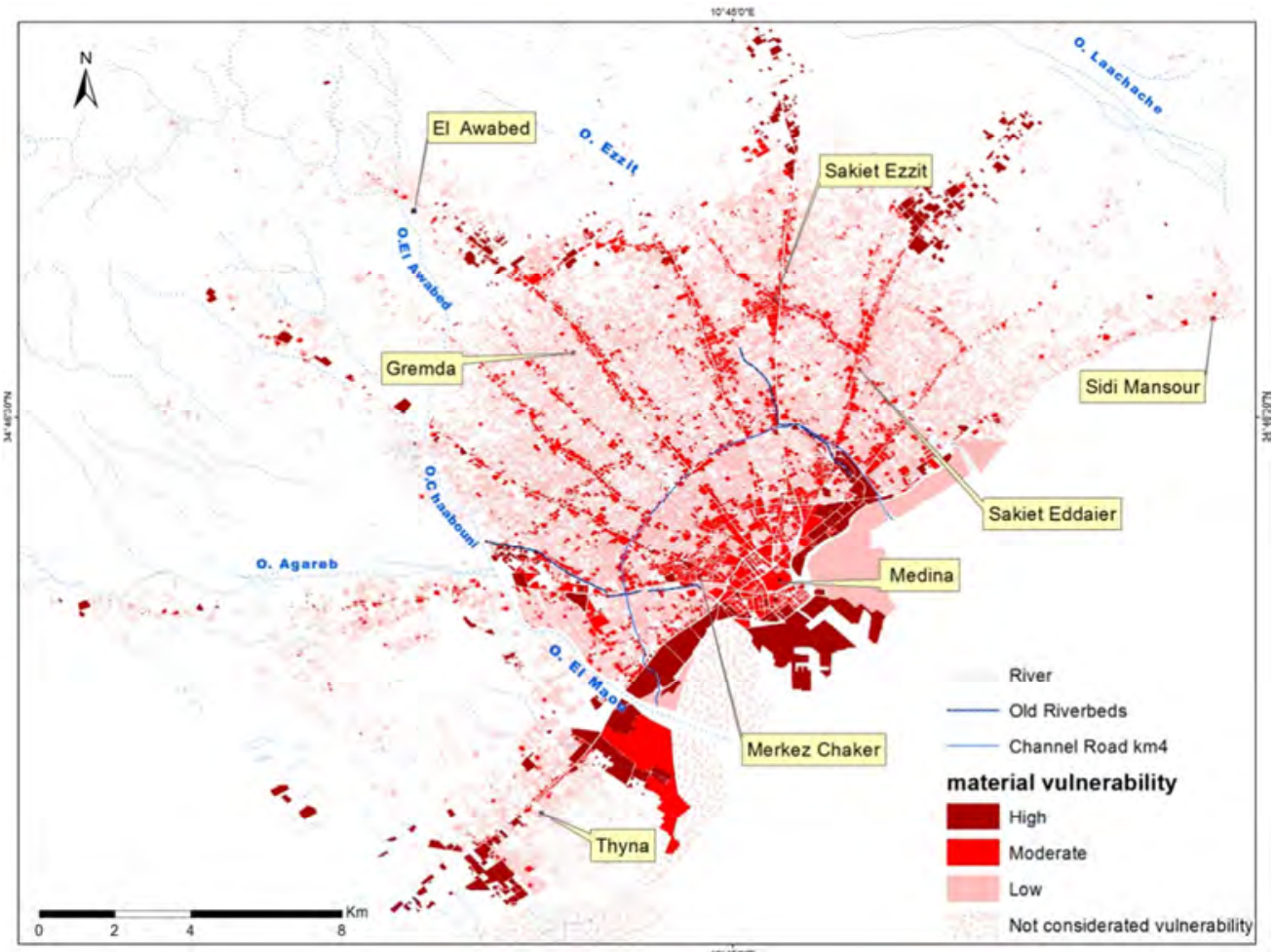

Figure 13. Map of the material vulnerability of the urban area of Sfax. 


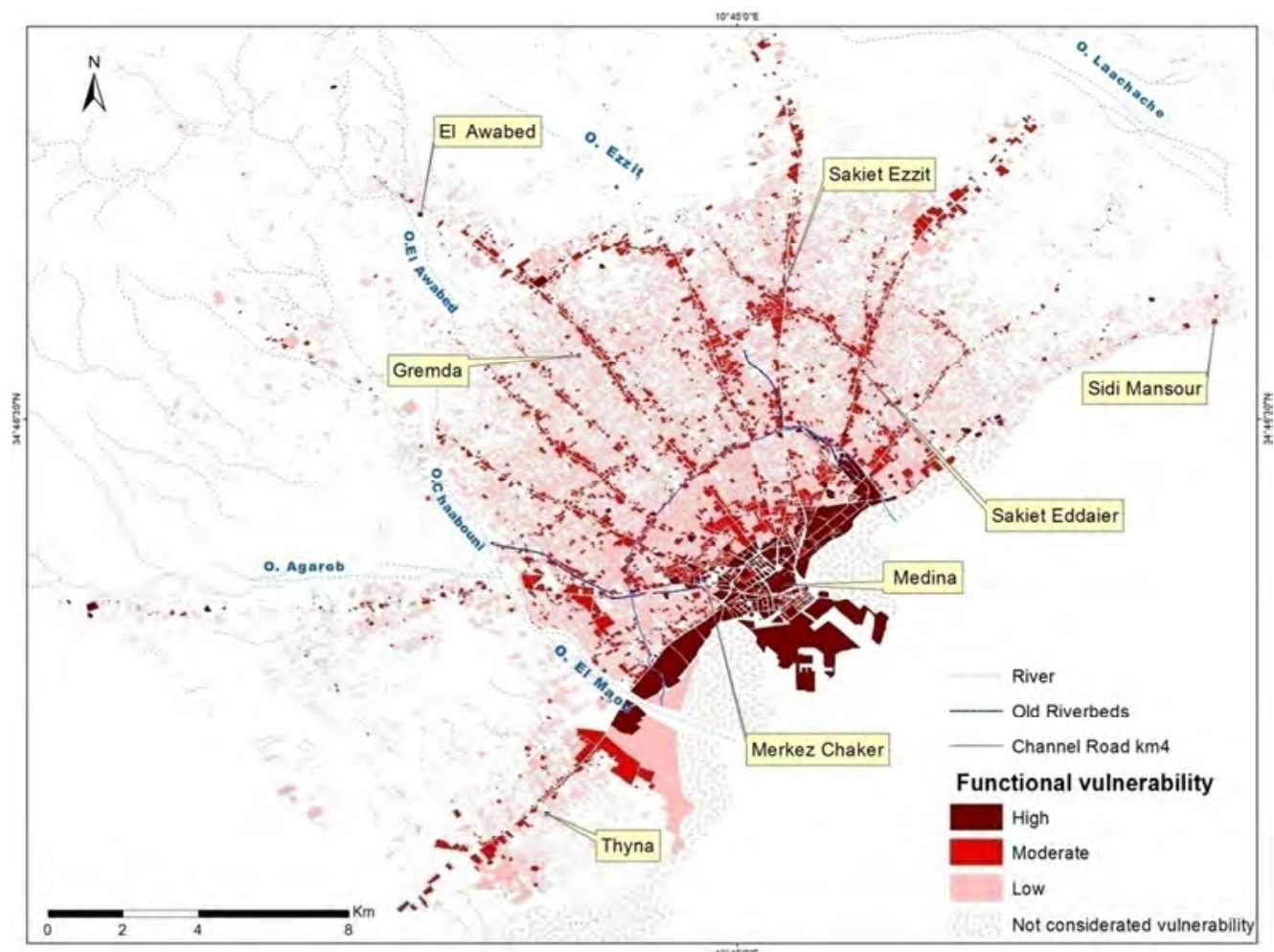

Figure 14. Map of the functional vulnerability of the urban area of Sfax.

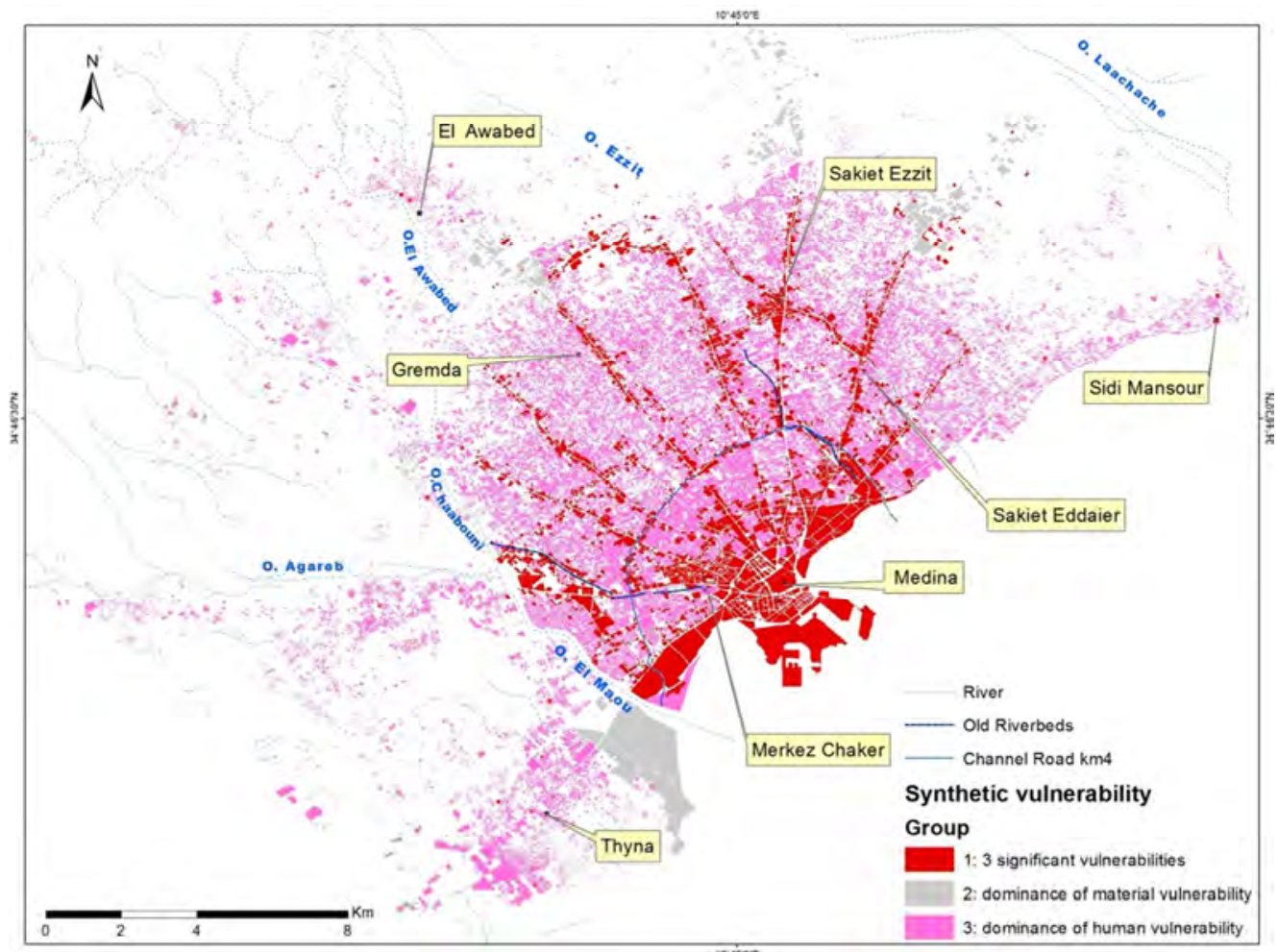

Figure 15. Map of the vulnerability of synthesis of the urban area of Sfax. (Cartography: Hmercha H. 2015).

According to the map of the human vulnerability (Figure $\mathrm{n}^{\circ} 12$ ), this one looks high in the littoral zones topographically low where the streaming, some popular quarters converge on the northern and southern city wings and in the suburban sectors located beyond the infrastructures of protections.

Figure $\mathrm{n}^{\circ} 13$ reveals that the central and suburban zones, because of accumulations and stagnations of water, and the radial sectors for the role of artificial axes of drainage of surface waters seem to be most vulnerable to material 
degradations. These same reasons explain the functional vulnerability, as the figure: 14 shows it.

The figure $n^{\circ} 14$ high lights that the central zone and some nodes in north and west of the city, intervene more in the paralysis or dysfunction of the city, because of the concentration of civil services, of economic activity and flow, any accumulation of water, on these zones induces an interruption of the activity and dysfunctions of local economic system and regional economic system.

Figure $n^{\circ} 15$ shows three various vulnerabilities groups of synthesis: first group of urban spaces or small islands having a vulnerability of synthesis in which the three types of vulnerabilities are important.

Then, a second group having a vulnerability of synthesis marked by a predominance of the economic vulnerability. Lastly, a third group (global vulnerability) in which the human vulnerability is more important than the two others.

The territories of the city where the three types of vulnerability are important correspond overall too many small islands located in the central and center neighbors sector, to radial and industrial areas and even some popular quarters on the northern and southern littoral. However, these spaces are relatively well protected by infrastructures: belt channel, several channels of evacuation of rain waters. Their vulnerability comes from the concentration of the industrial activities and services, of daily pendular mobilities event twice-a-day of the population which crosses the down town area and its periphery, of almost congest-lies of the lanes, phenomena on which transfers with their total blocking following the least down pours [6], as it was the case at the time as of 20092013 and 2015 pluviometric episodes.

\section{Conclusion}

At the end of this study, the results confirm the starting assumption: the infrastructures of protection of the urban area of Sfax mainly solved many years along its physical vulnerability, dependent on its low topography making of it a place of convergence of the flows of a basin at the rather vast risk. But they have become totally insufficient regarding the new vulnerabilities raised from the evolution of its urban morphology, the dysfunctions of the urban transportation system and the major concentration of the activities in central zone and on the radial extents. Much more than in new infrastructures, to overwhelm the risk of flood in the urban area, Sfax must from now aim to attenuate its vulnerability and seek solutions in a new generation, more globalized and anticipatory thinking way up on land-management: for example by the reinforcement of the poly-centrality on its periphery, or the adoption of a concerted Crisis Management Plan(CMP), applicable plan following each flood of these vulnerable zones, and comprising mainly an information and traffic organization in real time of the users of the city directing at the convenient period flows towards not submerged zones. Technological solutions are possible today, in particular via the mobile telephony (instantaneous diffusion of alarms and recommendations starting from information centers GIS), very largely used today in the Tunisian urban population.

\section{References}

[1] Bennasr, A. 2004: L'étalement urbain de Sfax. Revue tunisienne de géographie, 36, 39p.

[2] Bennasr, A. 2005: Aménagement urbain durable et gouvernance: Le cas de Sfax. Colloque SYFACTE/ GREGUM «Les villes au défi du développement durable», Sfax, 2005.

[3] Daoud A.1992: Apropos des inondations exceptionnelles d'octobre 1982 à Sfax. Revue Tunisienne de Géographie, 2122, p 11-31.

[4] Daoud A. 2005: Périurbanisation et risque d'inondation. Cas de l'agglomération de Sfax (Tunisie méridionale). Espaces Maghrébins, Revue de l'Union Géographique Marocaine. $\mathrm{n}^{\circ}$ 5-6. pp. 97-112.

[5] Daoud A. DahechS. 2012: La résilience de l'agglomération de Sfax face aux changements climatiques: essai d'évaluation Revue Climatologie. 2012 Numéro spécial, Climats et changement climatique dans les villes: $d u$ diagnostic spatialisé aux mesures d'adaptation. P 109-126.

[6] Daoud A 2013: Retour d'expérience sur les inondations dans l'agglomération de Sfax de 1982 à 2009: de la prévention à la territorialisation du risque Revue de Géographie de l'Est. Vol. $53 / 1-2$ pp 1-16.

[7] Laganier R. (Ed): 2006 Territoires, inondations et figures du risque. L'Harmattan. Itinéraires géographiques. Paris. 257p.

[8] Léone F, Meschin et De Richemond et Vinet F.2010: Aléas naturels et gestion de srisques. Coll. Puf Licence. 287p.

[9] Lelogiciel SIG Esri, EsriFranceArcGIS10.3.

[10] Lelogiciel SIG ENVI7.

[11] November V. 2002: Les territoires du risque, le risque comme objet géographique. Pub. Peter Lang. Berne. 332p.

[12] Preston, B. L., E. J. Yuen, and R. M. Westaway. 2011. Putting vulnerability to climate change on the map: A review of approaches, benefits, and risks. Sustainability Science 6 (2): pp. 177-202.

[13] Propeck Zimmermann E., Saint Gérand T., Bonnet E. 2007: Probabilités,risquesetgestionterritoriale:champsd'actiondes PPRT, Géocarrefour 82 (1-2), pp.65-76.

[14] Sakiss N. et Sassi N. 1982: Les inondations d'octobre 1982 à Sfax: Analyse statistique des données pluviométriques. Institut National de la Météorologie. Tunis.19 p. (ronéo).

[15] Saint Gérand T., Propeck Zimmermann E., Bonnet E., 2009: Nouvelles approches ergonomiques de la cartographie des risques industriels. Mappemonde No 96-4.

[16] Thouret JC. D'Ercole R. 1996: Vulnérabilité aux risques naturels en milieu urbain. Cah.Sci.Hum. 우 32. pp.407-422. 